\title{
Butantã versus mariante
}

\section{Butantã versus mariante}

DOI: $10.46814 / \operatorname{lajdv3n5-005}$

Recebimento dos originais: 01/07/2021

Aceitação para publicação: 31/08/2021

\section{Anna Paula Moura Canez \\ em Arquitetura PROPAR/UFRGS}

Instituição de atuação atual: Universidade Federal do Rio Grande do Sul, Faculdade de Arquitetura, Programa de Pós-Graduação em Museologia e Patrimônio

Endereço completo: Faculdade de Arquitetura - Rua Sarmento Leite 320, Porto Alegre - RS - Brasil, CEP 90050-170

E-mail: annapaulacanez@yahoo.com.br

\author{
Alex Carvalho Brino \\ Mestre PROPAR/UFRGS \\ Instituição de atuação atual: UNISC, Curso de Arquitetura e Urbanismo \\ Endereço completo: Av. Independência, 2293 (Bloco 52) Universitário, Santa Cruz do Sul - RS - \\ Brasil, CEP 96816-501 \\ E-mail: alexbrino@yahoo.com.br \\ Débora Saldanha de Avila \\ Mestre PPGAU UniRitter/Mackenzie \\ Instituição de atuação atual: IMED, Curso de Arquitetura e Urbanismo \\ Endereço completo: Rua Marquês do Pombal, 940, ap. 501, Porto Alegre - RS - Brasil, CEP 90540- \\ 000 \\ E-mail: arqdeboraavila@gmail.com

\section{Carolina Gottert Knies} \\ Mestre PPGAU UniRitter/Mackenzie \\ Endereço completo: Rua Saldanha Marinho 33, ap. 104, Lajeado - RS - Brasil, CEP 95900-000 \\ E-mail: carol_knies@hotmail.com
}

\section{RESUMO}

Trata-se de um estudo com foco no projeto como investigação de duas casas construídas em São Paulo, uma repetidamente identificada como pertencente à Escola Paulista Brutalista e a outra celebrada em diversas e recentes publicações como exemplar no universo contemporâneo da arquitetura brasileira, construídas em momentos muito distintos da nossa história. A primeira é a chamada Casa Butantã (1964-1966), pois situada no bairro que lhe deu o nome, de Paulo Mendes da Rocha - em realidade, duas casas lado a lado, uma realizada para o próprio arquiteto e a outra para a sua irmã, e a segunda é a casa Mariante, projetada 37 anos depois (2001-2002) por Angelo Bucci, do SPBR Arquitetos, e Marta Moreira, Fernando de Mello Franco e Milton Braga, do MMBB Arquitetos, localizada dentro de um condomínio fechado, distante 40 quilômetros do centro de São Paulo. O objetivo do trabalho foi buscar decifrar as duas obras escolhidas para análise, compreendê-las através de descrições apoiadas graficamente em material produzido pelo grupo de trabalho, cujo foco principal foi o saber propriamente arquitetônico. Revelar escolhas e descobrir o conceito, partindo do que suscitam através 
do redesenho e da revisão da bibliografia existente e, aí sim, compará-las com o propósito de apontar caminhos convergentes e divergentes.

Palavras-chave: Casa Mariante e Casa Butantã, Paulo Mendes da Rocha, MMBB.

\section{ABSTRACT}

This is a study focusing on the project as an investigation of two houses built in São Paulo, one repeatedly identified as belonging to the Paulista Brutalist School and the other celebrated in several recent publications as exemplary in the contemporary universe of Brazilian architecture, built at very different times in our history. The first one is the so-called Butantã House (1964-1966), since it is located in the neighborhood that gave it its name, by Paulo Mendes da Rocha - in reality, two houses side by side, one built for the architect himself and the other for his sister, and the second is the Mariante house, designed 37 years later (2001-2002) by Angelo Bucci, from SPBR Arquitetos, and Marta Moreira, Fernando de Mello Franco and Milton Braga, from MMBB Arquitetos, located in a private condominium 40 kilometers from downtown São Paulo. The objective of the work was to decipher the two works chosen for analysis, to understand them through descriptions graphically supported by material produced by the working group, whose main focus was the architectural knowledge itself. Revealing choices and discovering the concept, starting from what they raise through the redesign and the revision of the existing bibliography and, then, comparing them with the purpose of pointing out convergent and divergent paths.

Keywords: Casa Mariante and Casa Butantã, Paulo Mendes da Rocha, MMBB.

\section{INTRODUÇÃO}

Com projetos distanciados cronologicamente em mais de três décadas e meia, as casas Butantã e Mariante apresentam na essência de sua concepção similitudes que vão além da aparente forma prismática elementar elevada sobre quatro apoios e da materialidade explicitada pelo uso do concreto aparente. Em contrapartida, os contextos distintos que acabaram por balizar as decisões projetuais conduzem a justificativas não coincidentes mesmo que as soluções pareçam, em um primeiro momento, semelhantes e originadas em um problema comum. Pesando as coincidências está o fato de ambos os projetos terem sido desenvolvidos por arquitetos radicados em São Paulo e implantados na região metropolitana da capital paulista. As Casas Gêmeasi - visto se tratar de duas casas em lotes contíguos com projetos praticamente idênticos -, localizadas no bairro Butantã, em São Paulo, foram projetadas por Paulo Mendes da Rocha no ano de 1964. A Casa Mariante localiza-se em um condomínio fechado no distrito de Aldeia da Serra, Barueri/SP. O projeto foi realizado conjuntamente, no ano de 2001, por Marta Moreira, Fernando de Mello Franco e Milton Braga, do MMBB Arquitetos, e por Angelo Bucci, do SPBR Arquitetos. 

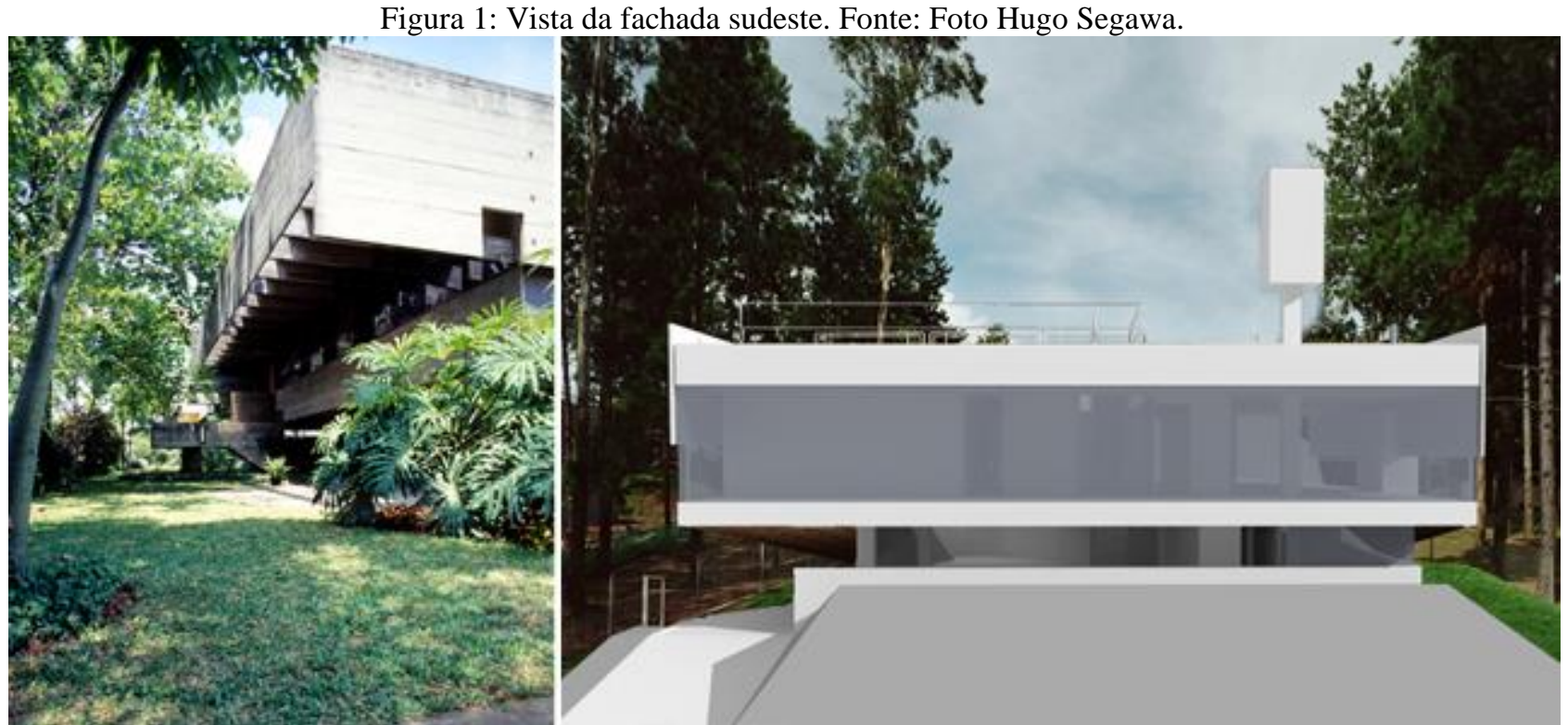

Vista frontal. Fonte: Desenho sobre fotografia de Carolina G. Knies.

As casas que Mendes da Rocha projetou para si próprio e sua irmã na década de 1960 transpõem no discurso o ideal de uma geração que entendia a arquitetura como agente transformador da sociedade, como claramente explicitou o arquiteto.

Queria tanto fazer uma coisa pré-fabricada, a época demandava tanto isso. Discutia-se tanto isso, habitação para todos, construção em massa. Muita não é o caso, porque não é bom, mas em quantidade suficiente para alimentar a industrialização na construção. Para fugir da miséria da obra, como conhecemos, do operário sem qualificação, coisas do tipo ${ }^{\mathrm{ii}}$.

Por outro lado, distante das questões ideológicas presentes no cenário nacional durante a construção de Brasília, o projeto da casa Mariante depara-se com aspectos contemporâneos recorrentes em se tratando do programa habitacional. A preocupação com a segurança faz com que a população especialmente a de classes média e alta - passe a optar por residir em condomínios fechados.

Estas questões e outras tantas, sem dúvida, permearam as decisões projetuais a que se relacionam. No entanto, o artigo pretende abordar principalmente as soluções de projeto propriamente ditas, com ênfase nos aspectos técnico-construtivos e formais, concernentes ao programa e ao espaço da habitação. Assim, o projeto apresenta-se como o meio de investigação das proposições. Como ressalva, assinala-se que a casa Butantã será tratada no singular, já que se analisará uma unidade: a solução projetual referente à casa do arquiteto, localizada no lote de esquina.

Situada em um lote urbano, plano, de 37x23 metros e de esquina, a meio quadrante, com a testada nordeste voltada para a Rua Eng. João de Ulhoa Cintra e a noroeste para a Rua Sant Getz, a residência do Butantã está implantada na região mais centralizada do lote. O programa foi desenvolvido em dois pavimentos, sendo que no térreo localizam-se os espaços de apoio, abrigo para os carros e 
piscina, enquanto que os sociais e íntimos foram contemplados no segundo pavimento. A relação da obra com o entorno ocorre de modo aberto, ou seja, há uma continuidade espacial e visual desde o interior até o espaço público, no entanto, o respeito à topografia original estabelece um limite entre o público e privado, conforme relata o arquiteto Paulo Mendes da Rocha, “cortei o território da colina só por baixo da casa, criando um patiozinho estrategicamente protegido de modo que não aparecesse como uma ofensa àquela colina e ao traçado da rua existente." iii Tal delimitação restringe parcialmente as visuais da área de apoio, pois todo este setor está protegido por um talude de aproximadamente 1,50 metros em relação ao nível da calçada.

Por outro lado, a residência Mariante insere-se em lote de 39x20 metros junto a um contexto urbano especial, pois o terreno encontra-se em condomínio fechado e usufrui de outra condição urbana, logo, as transições que ali ocorrem são entre o espaço semi-público e o espaço privado. Tanto a condição de meio de quadra, quanto a topografia em aclive, diferem de modo significativo da condição da residência do Butantã. A orientação solar é outro condicionante importante, com frente e vista para sudoeste, o terreno possui como atrativo especial a possibilidade de contemplar o pôr do sol. Volumetricamente em dois pavimentos, a casa se distribui com sua área de serviço em pavimento semienterrado, toda a área de convívio está contida no segundo pavimento e sua cobertura abriga espelho d'água e terraço. A condição de relação da área de apoio com a via de acesso é limitada pela presença de um talude que guarda reminicências do terreno natural, com aproximadamente 1,10 metros acima da cota da calçada e 1,40 metros acima do piso, todo o restante do terreno é de acesso extritamente privado.

Deste modo, percebe-se que, embora os terrenos apresentem dimensões aproximadas, suas condições urbanas, topográficas e de orientação solar diferem completamente. No entanto, talvez a maior diferença esteja no modo de conexão das residências com os espaços público e semi-público. No caso da Butantã, o talude permite alguma visualização do interior do lote a partir da rua, já o acúmulo do aclive natural, mais a remodelação, proposta na casa Mariante, restringe totalmente a percepção do pavimento de apoio, dando a impressão de que a residência desprende-se do solo. Em qualquer dos casos, a guarda de veículos encontra-se no pavimento inferior. Ainda no térreo, estão outros compartimentos de apoio como banheiros de serviço, dormitórios para funcionários e áreas de armazenamento. 
Figura 2: Vista lateral da casa Butantã. Fonte: Foto Hugo Segawa.

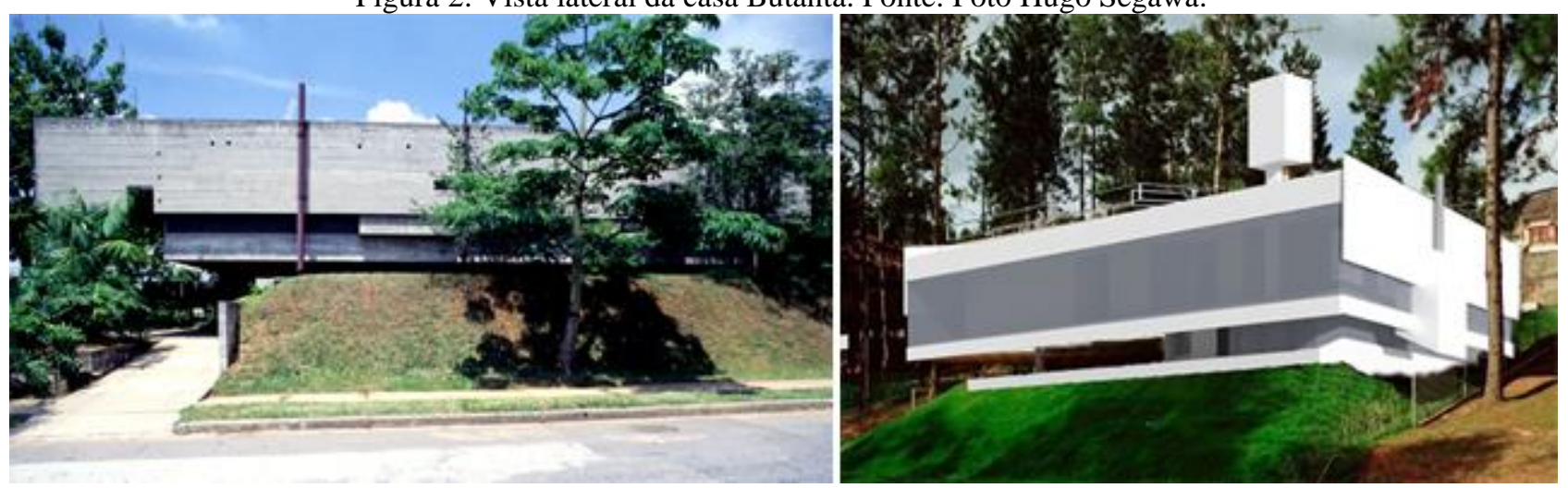

Casa Mariante. Fonte: Desenho sobre fotografia de Carolina G. Knies.

O pavimento principal da Butantã está organizado em três faixas paralelas à Rua Sant Getz, com duas delas - situadas nas bordas, junto às esquadrias - tratadas como espaços contínuos. Já a porção central da planta abriga os espaços fragmentados. A primeira faixa, junto à via, abriga os espaços de uso social. Dormitórios e cozinha localizam-se na faixa central. A varanda, funcionando como gabinete, ocupa a última faixa e se abre para o pátio dos fundos.

A residência de Barueri possui uma distribuição interna organizada em uma faixa na face noroeste somada a um setor central e a outro, periférico. A faixa noroeste é destinada aos dormitórios e escritório, o núcleo da planta contém as áreas molhadas, já o perímetro, destina-se ao uso social.

Nas duas casas, uma sucessão de condicionantes justifica uma solução ou outra, dentre estas, se destacam a orientação solar, a inserção urbana e o fato da casa servir ao próprio arquiteto, no caso da Butantã. Buscando um diálogo com a rua principal, Mendes da Rocha localiza o setor social junto à fachada da Rua Sant Getz e aproveita a condição de todos os espaços principais localizarem-se no último pavimento para utilizar a iluminação zenital como solução dos dormitórios, fato este que exige do usuário uma apurada condição de percepção arquitetural. A residência de MMBB e Bucci estabelece solução distinta; os dormitórios na borda do prédio indicam um usuário convencional. A sequência de espaços sociais de modo perpendicular à vista e por consequência à frente do lote se justifica tanto por uma busca de uma melhor orientação solar, quanto de melhores visuais. Para tal configuração de planta, os dormitórios poderiam ficar ao nordeste, no entanto, estariam voltados aos fundos do lote, sem qualquer possibilidade de contemplação da paisagem. Deste modo, a solução voltada para noroeste atende tanto a orientação geográfica, quanto a visual de perspectiva mais ampla. 
Figura 3: À esquerda, projeto da casa Butantã e a direita projeto da casa Mariante.
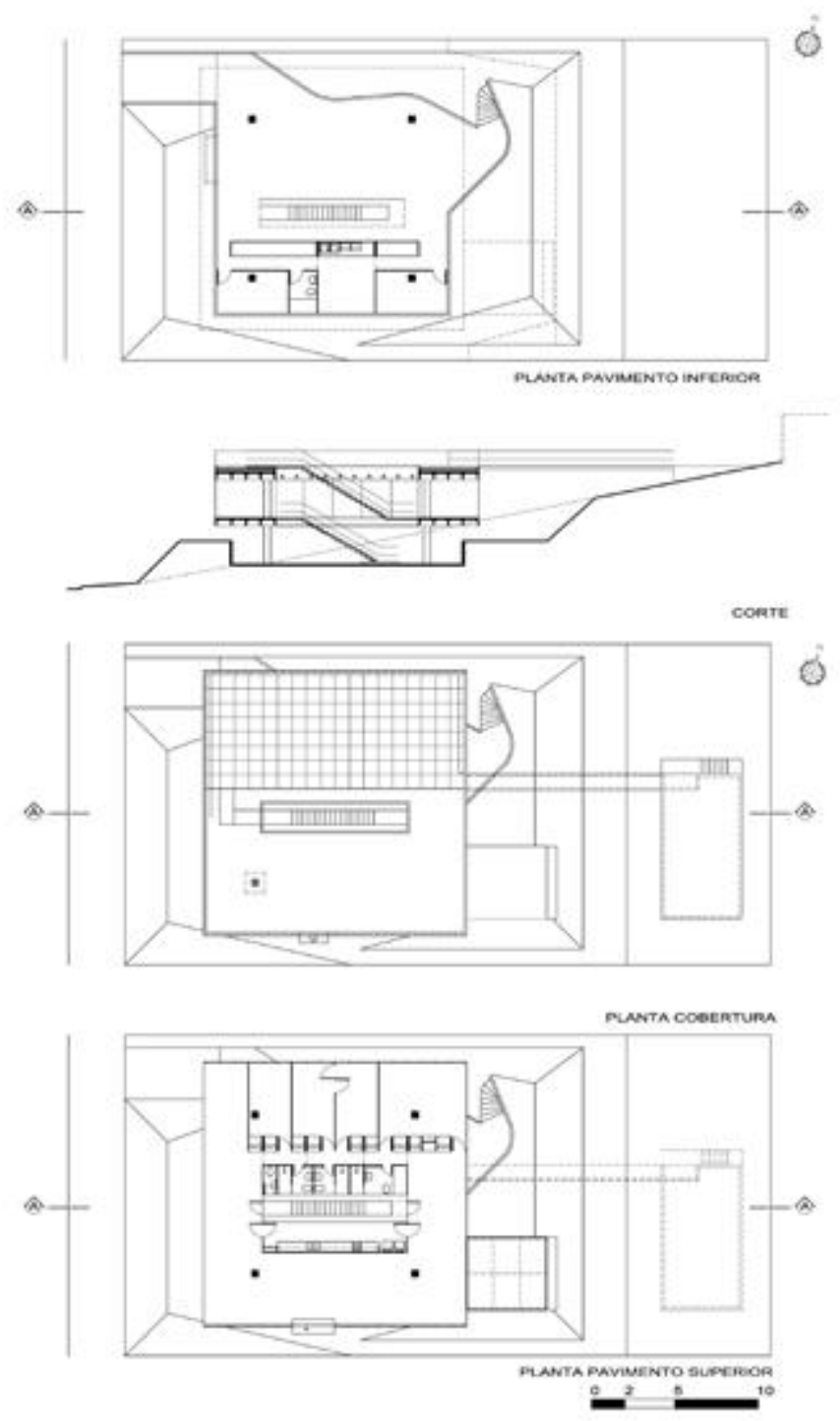

Fonte: Redesenhos de Débora Saldanha de Avila.

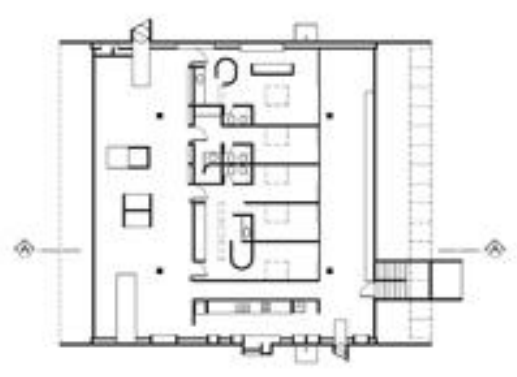

PLANTA PAMENGSTO SUPERIOG

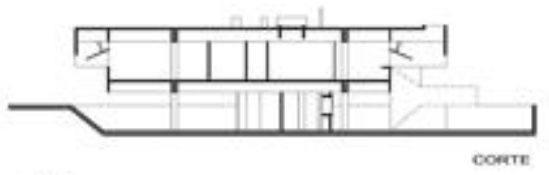

(ט)

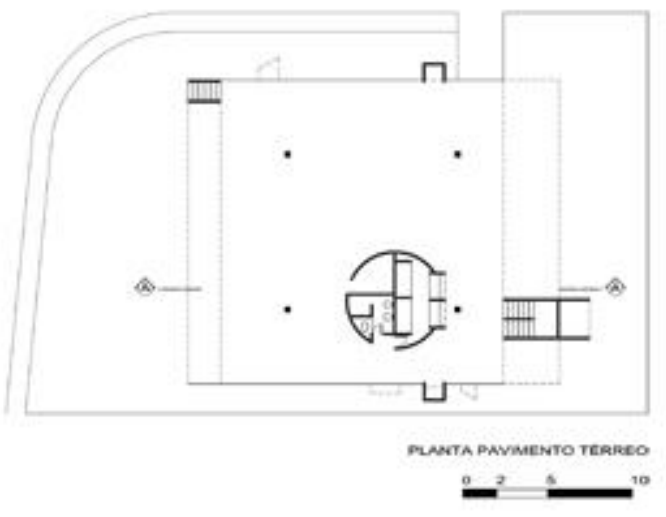

Quanto ao programa, em ambos os casos trata-se de residência unifamiliar, com amplo espaço de convívio onde acontecem especialmente o estar e as refeições. O modo como este ambiente se relaciona com o exterior na casa em Barueri demonstra não haver constrangimento em expor o cotiano da família a quem não faz parte dele. A permeabilidade visual é marcante, permitindo tanto que se contemple a paisagem a partir do interior, quanto se visualize boa parte da residência por quem transita em seus limites. De outra maneira, a proposta de Mendes da Rocha, possibilita uma ampla apreensão do exterior por quem se encontra dentro da casa, porém, mantém a privacidade dos usuários, através do modo como são solucionados os planos das fachadas e a projeção da cobertura. A introversão proposital da casa Butantã visa preservar o convívio familiar. As materialidades internas das residências amplificam este posicionamento, pois o branco interior da residência em Barueri aumenta 
a transparência da casa, já o concreto, que possui tonalidade escura, propicia um espelhamento maior das esquadrias, principalmente durante o dia.

Quanto à forma como se resolvem os dormitórios, no projeto de Mendes da Rocha a solução é peculiar, diferindo completamente do padrão das residências tradicionais dos arredores. Os cinco dormitórios têm acesso direto às áreas de estar, sem circulações intermediárias, e não dispõem de aberturas nas faces laterais da casa, sendo estas zenitais. Os banhos conformam espaços contíguos aos dormitórios, igualmente com aberturas zenitais. Contrariando a preferência mais contemporânea de banheiros exclusivos, a solução adotada na casa Mariante prevê três cômodos voltados a uma circulação de distribuição destinada ao acesso de dormitórios e banhos. Porém, com a possibilidade de mantê-los mais reservados, através de portas deslizantes que, quando fechadas, tornam os cômodos de uso exclusivo.

A cozinha na casa Butantã encontra-se na periferia da planta, ainda assim, podendo ser acessada diretamente a partir dos espaços de convívio. Já na proposta dos anos 2000, percebe-se a aproximação da cozinha ao cotidiano da família. O cômodo fica em local privilegiado da casa, em seu núcleo central, circundado pelos espaços de convívio.

A circulação vertical, no caso da Mariante, é explorada através de sua posição central em planta e da permeabilidade visual possibilitada pelo uso do vidro na vedação dos cômodos que a envolvem. Já na solução adotada por Mendes da Rocha, a circulação vertical é periférica, próxima aos espaços de apoio, como a cozinha. Em ambos os casos, a relação entre o acesso de veículos e o acesso à residência ocorre de modo similar, tendo, a escada, uma intenção plástica evidente.

Figura 4: Vistas internas da casa Mariante.

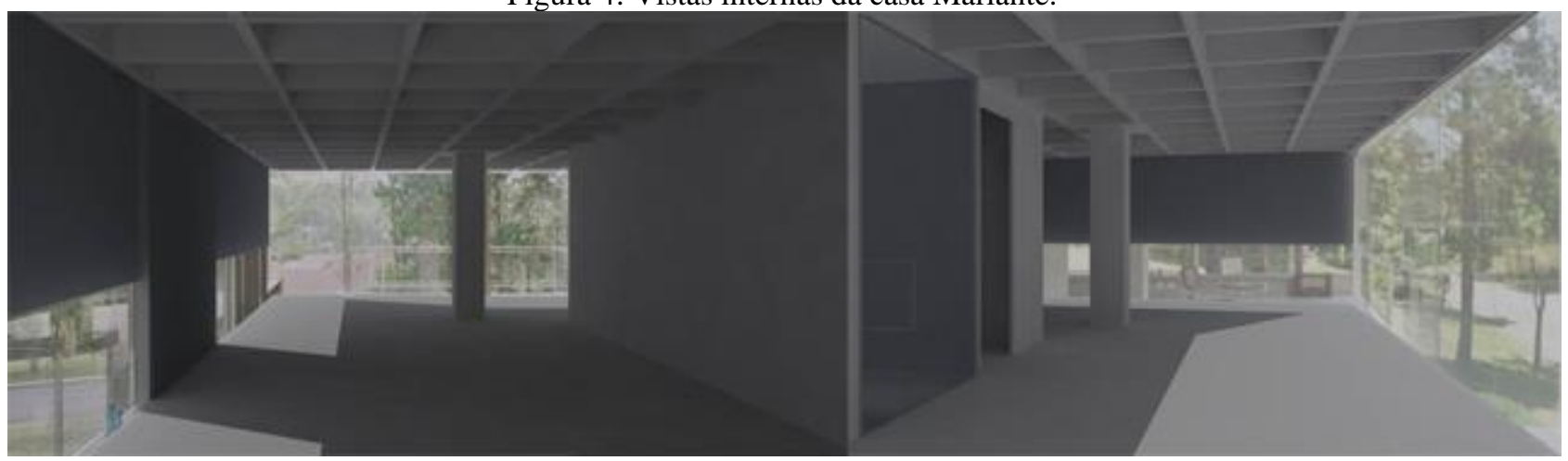

Fonte: Desenhos sobre fotografia de Carolina G. Knies.

As questões técnico-construtivas talvez tenham o maior número de convergências entre os projetos, ainda que as intenções que as motivam sejam distintas. Em qualquer das propostas, prevalece o uso do concreto armado e aparente. Uma das principais intenções de Mendes da Rocha ao adotar o material era ensaiar o uso de elementos pré-fabricados, mesmo que neste caso os elementos tenham 
sido executados in loco. No projeto da casa Mariante são valorizadas as virtudes do concreto armado, como a possibilidade de controlar de modo mais preciso a obra em função da racionalidade que este pressupõe.

A estrutura acontece, em ambos os casos, a partir da solução dos quatro pilares que suspendem o prisma principal e liberam o solo. Na Butantã tal solução se deve entre outras razões a resistência do terreno. Mendes da Rocha afirma: “O terreno na várzea do Rio Pinheiros é, digamos assim, frouxo. Era interessante concentrar cargas dentro de certos limites; por isso são quatro pilares de cem toneladas cada um." ${ }^{\text {iv }}$ Deste modo percebe-se que o esforço estrutural adotado para a solução do projeto ultrapassa a questão estética ou de mero desejo, não que estas também não estejam presentes, mas possuem um sentido técnico importante. O posicionamento dos pilares também demonstra o domínio técnico e plástico do arquiteto. Com o objetivo de otimizar a estrutura, Paulo Mendes adota o balanço equivalente a meio vão central nos dois sentidos, deste modo, ocorre um equilíbrio entre as áreas de contribuição da estrutura, todos os pilares recebem o mesmo carregamento, pelo menos, no que se refere ao peso próprio da estrutra. Isto ocorre tanto em relação às vigas que se apóiam nos pilareas, quanto em relação às nervuras que se apóiam nestas vigas. Embora o terreno de Barueri não apresente a mesma condição de solo, a solução estrutural adotada foi similar, no entanto, a proporção do balanço utilizado neste caso é 1/3 do vão central e a laje nervurada em um sentido é substituída por outra nervurada nos dois sentidos. Neste caso, o pilar se conecta a laje através de um capitel embutido na própria laje, obtido pelo preenchimento integral do espaço de uma cubeta.

Outra diferença está no dimensionamento estrutural, pois conforme relata o arquiteto:

[...] a laje calculada pelo eng. Shiegeo Mitsutani, levava o cálculo a tal refinamento que não respeitava a norma. Assim se combinou. Ele disse: vamos fazer uma coisa? Não vamos respeitar o coeficiente de segurança da norma, você concorda? Vamos calcular! ${ }^{\prime}$

O sistema de cálculo desta estrutura foi considerado como uma estrutura hiperestática, pois todo o concreto foi moldado in loco o que permitiu a redução de alturas e espessuras dentro de todo o sistema. Mas, segundo Paulo Mendes da Rocha, a casa poderia ser industrializada, e para tanto as espessuras se ampliariam por motivo de transporte e montagem. A altura final da obra teria ao menos um metro a mais pela questão da sobreposição das peças de vigas e nervuras independentes. 
Figura 5: Sequência de montagem da estrutura das duas casas.
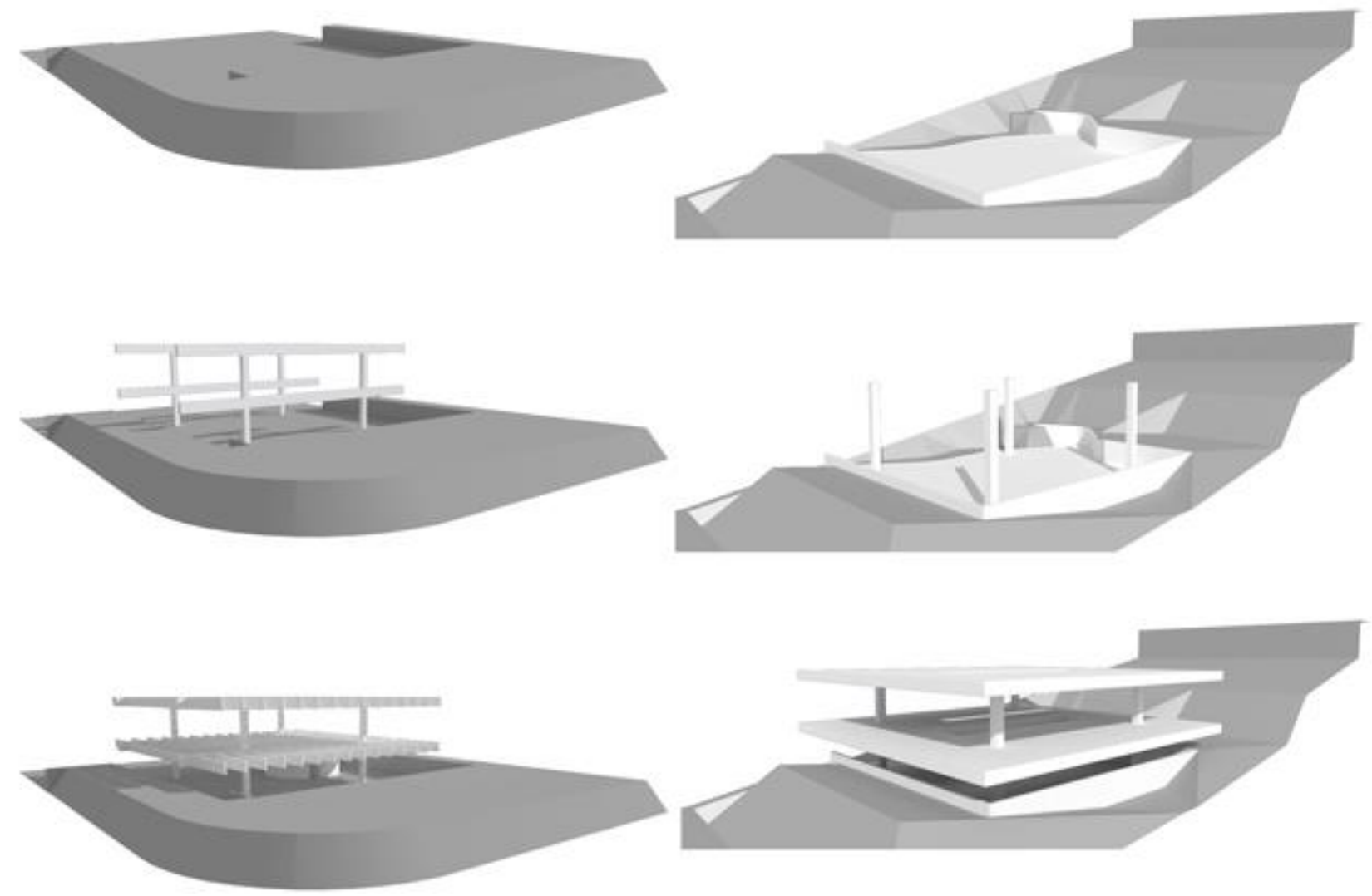

Fonte: Desenhos de Carolina G. Knies.

A casa Mariante está relacionada à industrialização pelo viés do rigor e geometrização do projeto e pela técnica mais apurada de concretagem, pois a ausência da lógica de uma viga transportando os carregamentos para os pilares impede a decomposição do sistema. Ainda cabe registrar que as nervuras nos dois sentidos ampliam a rigidez da laje e possibilitam a redução da seção da nervura, porém, ainda assim, a seção da casa Butantã é menor.

Outro destaque é a posição das circulações verticais do ponto de vista estrutural. No caso da Butantã, a escada surge como elemento independente que não se apoia, nem perfura a estrutura principal, com o objetivo de não interromper parte do sistema, logo, evita a sobrecarga em alguma região específica. No projeto de Barueri, a escada está localizada na região central e deste modo, como o dimensionamento dos balanços é igual à metadea do vão central, justamente neste ponto é o local mais favorável para posicionar uma perfuração, como é o caso. 
Figura 6: Aberturas zenitais e esquadrias sudeste na casa Butantã.

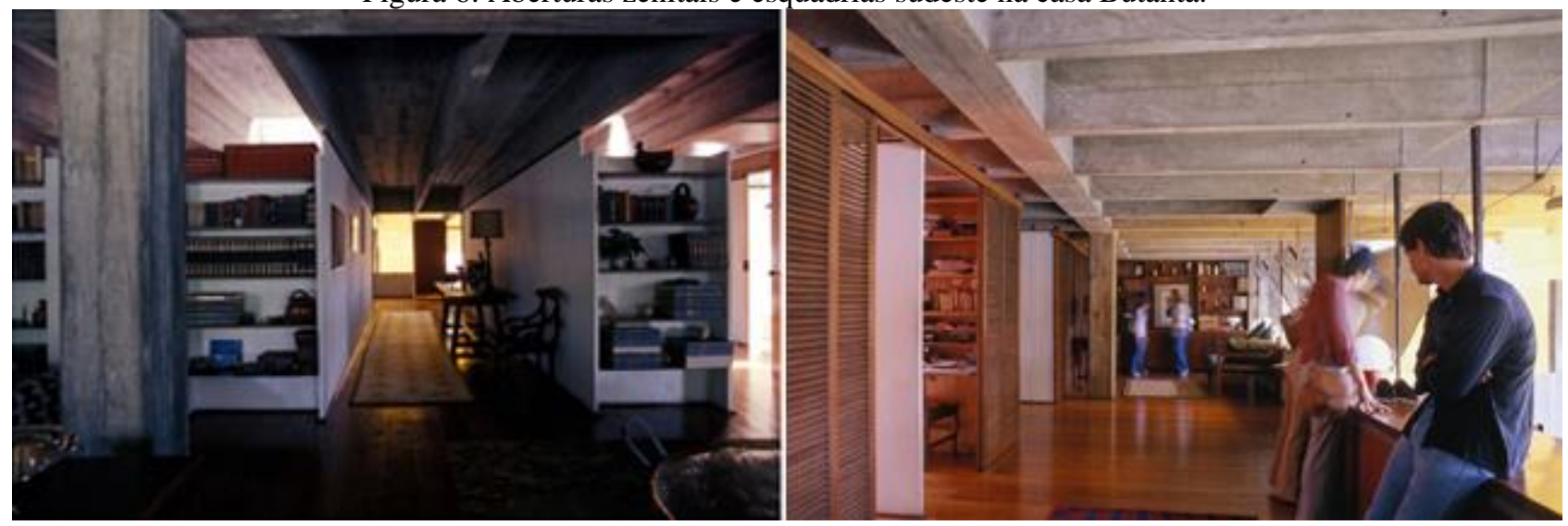

Fonte: Foto Hugo Segawa.

Quanto a aspectos relacionados ao conforto ambiental, os projetos demonstram algum distanciamento. A solução adotada por Paulo Mendes da Rocha apresenta uma proteção horizontal constituída pelo avanço da cobertura na direção noroeste, com o objetivo de controlar a incidência na esquadria social, já a fachada oposta no final do mesmo prolongamento da cobertura foi colocado um plano vertical que funciona como rebatedor junto à esquadria próxima da área de trabalho. As perfurações zenitais complementam a iluminação natural de modo comedido à região dos dormitórios.

A casa Mariante, que se encontra em um alto de serra, possui as fachadas voltadas a sudeste e nordeste, que correspondem à frente e fundos do lote respectivamente, vedadas integramente por panos de vidro. A escolha do material sob tais circunstâncias de insolação, e a opção por não se utilizar nenhum sistema que a condicione, permite que o interior da casa seja atingido de forma direta pelos raios solares durante boa parte do dia. Em contrapartida o uso do espelho d'água na cobertura e a disposição das aberturas, possibilitando a ventilação cruzada, amenizam os prováveis efeitos da carga térmica recebida.

Outras escolhas de projeto convergem, mas não necessariamente as razões que as motivaram. As empenas em ambas as casas são resolvidas duas a duas, as laterais e as frontais/de fundos, alternando fachadas quase totalmente opacas e fachadas com amplas esquadrias contínuas, porém no projeto de Mendes da Rocha as janelas em fita possuem peitoril, decisão projetual associada à questão de privacidade pretendida. Na solução adotada pelo MMBB e Bucci, a transparência do vidro prevalece nas fachadas de frente e fundos. As fachadas laterais possuem esquadrias contínuas em altura intermediária-baixa, não coincidente com o campo visual de um usuário em pé, em ambos os casos foi priorizada a altura de quem utiliza o mobiliário.

Os variados pontos vazados nas fachadas laterais da casa Butantã, atrelados ao desalinhamento intencional dos planos de uma mesma fachada configuram uma engenhosa solução que explora situações de luz e sombra no interior da edificação. Já a ausência de caixilhos nas esquadrias utilizadas 
na casa em Barueri sinaliza a preocupação com a essencialidade do projeto, a supressão de supérfluos. Os móveis fixos executados em concreto na obra de Mendes da Rocha e o mobiliário-divisória utilizado na casa Mariante, demonstram que o problema da arquitetura é indissociável da escolha de móveis e objetos, assim como salientavam os ensinos da Bahaus. A enfática solidez da casa Butantã contrasta com o equilíbrio entre vidro e concreto da residência em Barueri. Mas em qualquer das situações evidencia-se o domínio tecnológico que nasce e se desenvolve acompanhando os avanços de cada etapa projetual. A ideia de unidade e intensidade formal explicitada em ambas às obras sinaliza que a recriação do espaço habitacional pode reduzir-se ao limite estrito de forma e estrutura desde que haja ampla compreensão da técnica e a busca constante pela boa arquitetura. 


\section{REFERÊNCIAS BIBLIOGRÁFICAS}

Artigas, João Baptista Vilanova. Caminhos da arquitetura. São Paulo: Ciências Humanas, 1981. Bastos, Maria Alice Junqueira; Zein, Ruth Verde. Brasil: arquiteturas após 1950. São Paulo: Perspectiva, 2010.

Guerra, Abílio; Castroviejo Ribeiro, Alessandro José. “Casas brasileiras do século XX,” Arquitextos, São Paulo, $\quad 07.074, \quad$ Vitruvius, 2006 <http://www.vitruvius.com.br/revistas/read/arquitextos/07.074/335>.

Nobre, Ana Luiza. "Um em dois. As casas do Butantã, de Paulo Mendes da Rocha," Arquitextos, $\begin{array}{lllll}\text { São } & \text { Paulo, } & \text { 08.086, } & \text { Vitruvius, } & \text { jul }\end{array}$ <http://www.vitruvius.com.br/revistas/read/arquitextos/08.086/228>.

NOBRE, Ana Luiza; WISNIK, Guilherme; MILHEIRO, Ana Vaz. Coletivo. 36 projetos da arquitetura paulista contemporânea. Cosac Naify, São Paulo; $1^{\text {a }}$ edição, 2006.

Piñón, Helio. Paulo Mendes da Rocha. São Paulo: Romano Guerra Editora, 2002.

Solot, Denise Chini. Paulo Mendes da Rocha. Estrutura: o êxito da forma. Rio de Janeiro: Vianna \& Mosley, 2004.

Xavier, Alberto; Lemos, Carlos, Corona, Eduardo. Arquitetura moderna paulistana. São Paulo: Editora Pini, 1983.

Zein, Ruth Verde. Arquitetura brasileira, escola paulista e as casas de Paulo Mendes da Rocha. Dissertação (mestrado) - Universidade Federal do Rio Grande do Sul. Faculdade de Arquitetura. Programa de Pesquisa e Pós-Graduação em Arquitetura, Porto Alegre, BR-RS, 2000. Ori.: Comas, Carlos Eduardo Dias.

Zein, Ruth Verde. O lugar da crítica. Ensaios oportunos de arquitetura. São Paulo: ProEditores/ Ritter dos Reis, 2001.

Zein, Ruth Verde. A arquitetura da escola paulista brutalista 1953-1973. 2005. 2 v. (1 folha dobrada): il.; $28 \times 41 \mathrm{~cm}$ dobrada em 28x21 cm Tese (doutorado) - Universidade Federal do Rio Grande do Sul. Faculdade de Arquitetura. Programa de Pesquisa e Pós-Graduação em Arquitetura, Porto Alegre, BR-RS, 2005. Ori.: Comas, Carlos Eduardo Dias.

${ }^{\mathrm{i} E m}$ SOLOT, Denise Chini. Paulo Mendes da Rocha. Estrutura: o êxito da forma. Rio de Janeiro: Vianna \& Mosley, 2004.

iiPiñón, Helio. Paulo Mendes da Rocha. São Paulo: Romano Guerra Editora, 2002.p. 25.

iiiPiñón, Helio. Paulo Mendes da Rocha. São Paulo: Romano Guerra Editora, 2002.p. 24.

ivPiñón, Helio. Paulo Mendes da Rocha. São Paulo: Romano Guerra Editora, 2002 p. 24.

'Piñón, Helio. Paulo Mendes da Rocha. São Paulo: Romano Guerra Editora, 2002 p. 25. 